\title{
Level of Stress and Its Association with Socio-Demographic Factors among Medical Students of Rawalpindi Medical College
}

\author{
Dr. M. Kashif ${ }^{1} *$, Madiha Fatima ${ }^{2}$, Badur-un-Nisa ${ }^{3}$, Dr. Shazia Hassan ${ }^{4}$, \\ Irsa Ghazal ${ }^{5}$, Dr. Faiza Aslam ${ }^{6}$
}

\section{ABSTRACT}

Stress among medical students is a common experience. This cross-sectional study was conducted at Rawalpindi Medical College, Pakistan in 2015 to determine level of stress of students. To a sample of 292 students, semi-structured Performa along with Student-Life-StressInventory scale was applied. Data was analyzed using independent sample t-test and Pearson's chi square test at $5 \%$ level of significance. $25 \%, 52.7 \%, 22.3 \%$ students were mildly, moderately and severely stressed respectively. Statistically significant gender differences were observed in three domains of scale. In most of subscales the scores attained by male students were higher as compared to female students. Moderate stress being most commonly prevalent and was more common in female students as compared to male students.

Keywords: Stress, Undergraduate Medical/Education, Psychological

Students can experience stressful circumstances associated with interpersonal relationships, work, and academic. Stress could come in changed ways in an individual's daily life. Stress is similarly perceived as the body's reaction, both neurologically and physiologically, to adjust to a new form (Franken, 1994). Stress is a general term applied to numerous psychological like mental and physiological like bodily pressures experienced or felt by people throughout their lives (Gaurav Akrani 2011)

When we talk about the modification in life, we standardize ourselves to fit in the new condition. For a student, stress can be started by failure in academic or sports, financial problems, health

\footnotetext{
${ }^{1}$ Assistant Professor Institute of Psychiatry Benazir Bhutto Hospital, Rawalpindi Medical College Pakistan

${ }^{2}$ Clinical Psychologist Institute of Psychiatry Benazir Bhutto Hospital, Rawalpindi Pakistan

${ }^{3}$ Prosthetist and Orthotist Global Management Team, Rawalpindi, Pakistan

${ }_{5}^{4}$ Assistant Professor National University of Modern Languages Islamabad Pakistan

${ }^{5}$ Clinical Psychologist Institute of Psychiatry Benazir Bhutto Hospital, Rawalpindi, Pakistan

${ }^{6}$ Research Coordinator Rawalpindi Medical College, Rawalpindi Pakistan

*Responding Author
}

(C) 2016 Kashif, M, Fatima M, Nisa B, Hassan S, Ghazal I, Aslam F; licensee IJIP. This is an Open Access Research distributed under the terms of the Creative Commons Attribution License (http://creativecommons.org/licenses/by/2.0), which permits unrestricted use, distribution, and reproduction in any Medium, provided the original work is properly cited. 


\section{Level of Stress and Its Association with Socio-Demographic Factors among Medical Students of Rawalpindi Medical College}

problems or may be the loss of a family member or close friend. Such occasions which carry stress is called stressors. Stress is basically a fact of nature, which force from inside or outside the world that affect the individual. The individual may responds to stress in different ways that affect the individual, as well as their environment. Another Study which was conducted on medical students of Nigeria suggest that high levels of stress and psychological illness occur in health care profession students (Omigbodun O, Odukogbe, Yusuf OB, Bella 2006). A study conducted on the medical students of Saudi Arabia suggested that the medical student's education is supposed as being stressful, and the high level of stress may have a negative effect on learning and the cognitive functioning of students in a medical school. The study reveals that total prevalence of stress was $63 \%$, and the occurrence of severe stress was $25 \%$. The occurrence of stress was greater $(\mathrm{p}<0.5)$ among females $(75.7 \%)$ than among males $(57 \%)$. The prevalence of stress was higher during the early three years of study and among the female students (Hamza Abdulaziz, Ebrahim 2011). Similarly another study conducted in Nepal among the medical students of Manipal College of Medical Sciences, Pokhara reveals that overall prevalence of psychological illness was $20.9 \%$ and was higher among students of basic sciences (Sreeramareddy CT, Shankar PR, 2007 Aug). A comparative study was conducted in Bangladesh in which the overall prevalence of stress was found out. According to this study, the population was $54 \%$. Whereas the (53\%) of male and (55\%) of female were reported stress. In Year-III students (54\%) and year-IV (55\%) were noted suffering from stress (Eliza, MdZakirul, Abu Syed Md 2015). A study was conducted nationally which reveals that the incidence of apparent stress among the medical students was higher and this might affect not only their academic grades but also all stages of health and life. For coping with stress, there is basically a broad collection of strategies and these plans could play an important role in enabling students cope with stress (Farida, Naima, Farah 1999). A study was conducted among the students of Thailand and according to results of this study students who were suffer from stress is about (61.4\% ). Seventeen students (2.4\%) of them reported a high level of stress. So the prevalence of stress is highest among the third-year medical students ( R. Saipanis 2003).

Academic problems were originated to be a major root of stress among all students. The most dominant cause of academic stress was the test and exam. Many other sources are also discussed for medical school and their relationships. These findings can support medical teachers to understand more about stress among their students and guide the ways to the improvement in an academic context, which is highly important for student achievement.

A study was conducted on the physiotherapy students in Pakistan .The findings of this study revealed that females face more stressors specifically on pressures $(p<0.001)$, physiological, emotional $(\mathrm{p}<0.01)$ and behavioral $(\mathrm{p}<0.05$ Mean difference shows that prevalence of stress is greater in 4th semester of RCRS students (F. sabih 2013).Another study was conducted in Pakistan among the students of Allied health science. In which $25.1 \%$ of students were mildly 


\section{Level of Stress and Its Association with Socio-Demographic Factors among Medical Students of Rawalpindi Medical College}

stressed, 51.3\% moderately stress and 23.6\% were severely stressed. Moderate stress was commonly found and it was more common in female students as compared to male students (Badur-un-Nisa 2016)

Our study will help to develop greater personal awareness of student's types of personal and their academic stressors that they are suffering while being medical students. This understanding may inform policies and practices planned to reduce medical student's stress, and improve learning, retention and academic performance. Eventually the conclusions may increase the number of qualified undergraduates of Rawalpindi medical college, and enhance the quality of health care in the Pakistan.

\section{MATERIAL AND METHODS}

This cross-sectional study was accompanied at Rawalpindi Medical College, Rawalpindi from March 2015 to September 2016 after approval by Institutional Research forum and Ethical Review Committee of Rawalpindi Medical College. According to the reference study keeping expected proportion of stressed students as 88\% (F Sabih -2013), 95\% confidence interval and $5 \%$ absolute precision, then minimally required sample size according to WHO sample size calculator was calculated to be 168 but 292 students were involved. This Stratified Random sampling method was adopted to select the study participants, using attendance record register of each academic year as sampling frame work. Stratification was done based on academic year and discipline. SPSS generated random number list was used to select randomly were included. Informed verbal consent was taken from selected students. Data was collected using administered questionnaires technique through a structured, pretested performa comprising of socio-demographic background section and Student Life Stress Inventory (SLSI). Students suffering from Psychiatric illness or those using any psychotropic medication were excluded from the study. Questionnaire was administered to the medical students at Rawalpindi medical college and the duration was March to May 2015.

Socio-demographic section comprised of 18 items, which are related to student's personal and socio-demographic details. Whereas SLSI Scale consisted of 51 items listed in 9 sections indicating different types of stressors (frustrations, pressures, conflicts, self-imposed ,and changes stressors) and reactions to the stressors (physiological, emotional, behavioral, and cognitive). All information obtained in this study was kept strictly confidential. Data was analyzed through SPSS version 21. Descriptive statistics were calculated to find out the overall percentage and frequency of stress. According to this Mean and standard deviation (SD) was taken out from the list of all the sub-scales. Independent t-test and Chi-square was used to see the mean differences between female and male students in experiencing stress under graduate medical of RMC. Stress was categorized as mild, moderate and severe based on the standardized scores of scale.

(C) The International Journal of Indian Psychology, ISSN 2348-5396 (e)| ISSN: 2349-3429 (p) | 96 


\section{RESULTS}

Mean age of study participant was $21.01 \pm 1.87$.None of the student was found without stress, as results show that each and every student was experiencing some level of stress. Therefore stress was observed in all $292(100 \%)$ according to the Student Life Stress Inventory scale. Among total students $(\mathrm{n}=292)$ 73(24.7\%) were mild stressed, 154(52.2\%) were moderately stressed while 65 (22\%) were severely stressed.

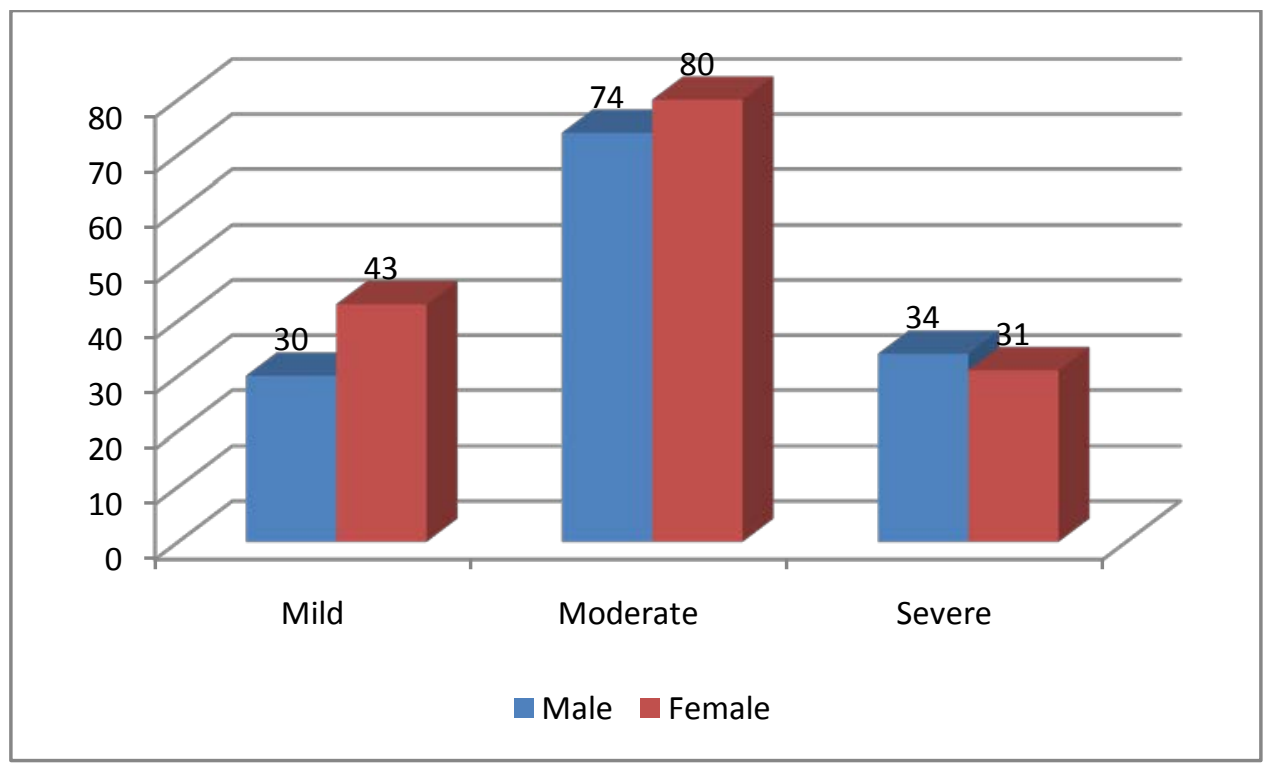

Figure 2: A bar chart displaying distribution of three levels of stress in medical student based on Gender wise ( $n=292)$.

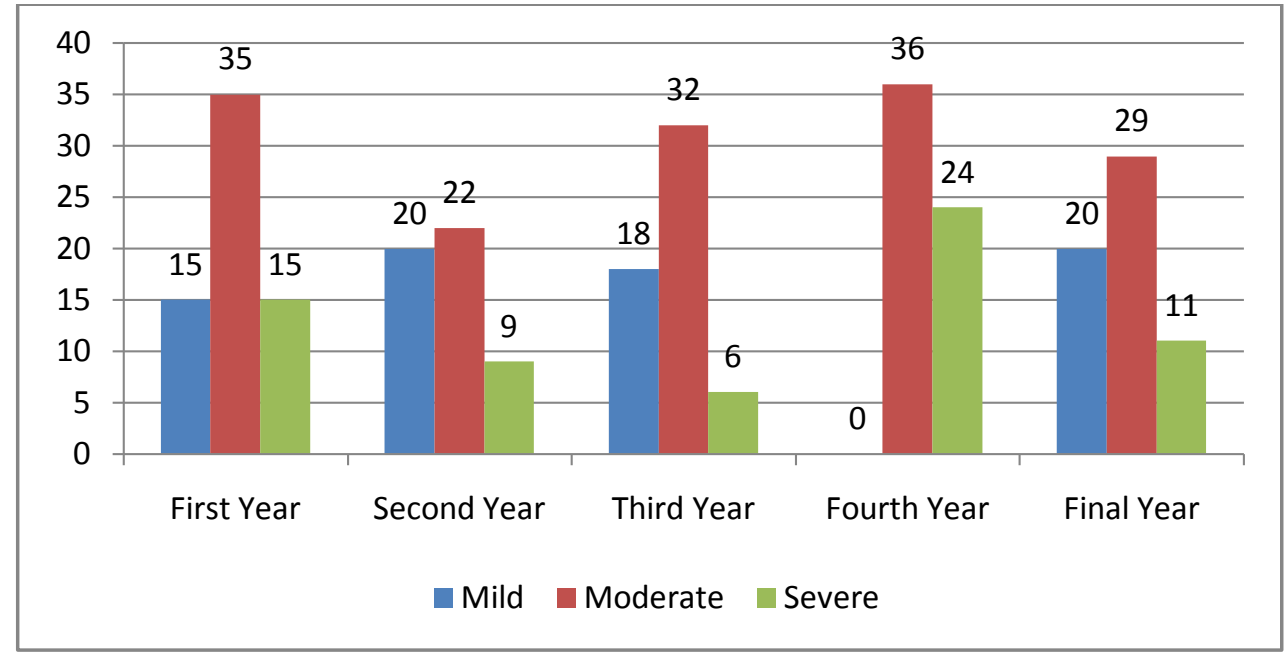

Figure: 3 A bar chart distribution of three levels of stress according to the years of students $(n=292)$ 


\section{Level of Stress and Its Association with Socio-Demographic Factors among Medical Students of Rawalpindi Medical College}

When levels of stress were observed according to distribution in five year of medical students then its shows each year has shown some level of stress, again $4^{\text {th }}$ year of students shows moderate stress and there is no statistically significant differences were observed (figure 3). This figure shows the differences between different semesters in experiencing stress level. These stress level were based on academic years of student that are five years in total.1st year student expressed 54\% moderate stress, 2nd year students expressed 43\% moderate stress, 3rd year students expressed $57 \%$ moderate stress, 4 th year students mostly expressed $60 \%$ moderate stress and 5th year students expressed $48 \%$ moderate stress(Figure-3). No statistically significant difference of stress was observed in distribution of three levels of stress in students on the basis of five year.

Table: 1 Score on subscale and total score of Student Life Stress Inventory for male and female medical students $(n=292)$

\begin{tabular}{|l|l|l|l|l|}
\hline Subscales & Male & Female & T-Score & P-Value \\
\hline Total Stressors & $68.81 \pm 13.95$ & $68.75 \pm 13.76$ & 0.03 & 0.97 \\
\hline Total Reactions & $76.21 \pm 19.54$ & $74.83 \pm 19.36$ & 0.60 & 0.54 \\
\hline Frustrations & $18.12 \pm 6.16$ & $16.29 \pm 5.76$ & 2.61 & $0.00^{* *}$ \\
\hline Conflicts & $11.35 \pm 4.90$ & $11.24 \pm 4.06$ & 0.219 & 0.82 \\
\hline Pressures & $11.82 \pm 3.19$ & $12.35 \pm 3.42$ & -1.36 & 0.17 \\
\hline Changes & $8.48 \pm 3.09$ & $7.97 \pm 3.16$ & 1.39 & 0.16 \\
\hline Self-imposed & $19.02 \pm 4.33$ & $20.88 \pm 5.39$ & -3.22 & $0.00^{* *}$ \\
\hline Physiological & $36.55 \pm 10.74$ & $35.33 \pm 12.38$ & 0.89 & 0.36 \\
\hline Emotional & $11.75 \pm 3.64$ & $12.55 \pm 3.60$ & -1.98 & 0.05 \\
\hline Behavioral & $21.51 \pm 8.22$ & $20.24 \pm 6.61$ & 1.46 & 0.14 \\
\hline Cognitive & $6.38 \pm 2.06$ & $6.70 \pm 2.16$ & -1.27 & 0.20 \\
\hline
\end{tabular}

**p-vale less than 0.05 highly statistically significant

Table: 1 shows that significant gender differences on the subscales in the mean scores of Rawalpindi medical college students. These findings reveal that females perceive more stress and are more disposed to reactions as compared to males t-test was applied for each subscale of SLSI Scale, where highly statistically significant tests were found for the subscale of frustrations and self-imposed. These findings also reveal that female's face more stressors especially on selfimposed and frustrations $(\mathrm{p}=0.00)$

Association of various socio-demographic and personal factors was explored. According to that stress was present but no statistically significant association was found (Table 2) 
Level of Stress and Its Association with Socio-Demographic Factors among Medical Students of Rawalpindi Medical College

Table 2: Association of various socio-demographic factors with severity of stress $(n=292$

\begin{tabular}{|c|c|c|c|c|c|}
\hline \multicolumn{2}{|c|}{ Sociodemographic and personal factors } & \multirow{2}{*}{$\begin{array}{l}\begin{array}{l}\text { Mild No } \\
(\%)\end{array} \\
30(10.3 \%)\end{array}$} & \multirow{2}{*}{$\begin{array}{l}\begin{array}{l}\text { Moderate No } \\
\text { (\%) }\end{array} \\
74(25.3 \%)\end{array}$} & \multirow{2}{*}{$\begin{array}{l}\begin{array}{l}\text { Severe No } \\
(\%)\end{array} \\
34(11.6 \%)\end{array}$} & \multirow{2}{*}{$\begin{array}{l}\mathbf{p}- \\
\text { values } \\
1.81\end{array}$} \\
\hline Gender & Male & & & & \\
\hline & Female & $43(14.7 \%)$ & $80(27.4 \%)$ & $31(10.6 \%)$ & \\
\hline \multirow[t]{2}{*}{ Boarding status } & Boarders & $38(13.0 \%)$ & $85(29.1 \%)$ & $35(12.0 \%)$ & \multirow[t]{2}{*}{.19} \\
\hline & Day scholars & $35(12.0 \%)$ & $69(23.6 \%)$ & $30(10.3 \%)$ & \\
\hline \multirow{2}{*}{$\begin{array}{l}\text { Percentages in last annual } \\
\text { exams }\end{array}$} & $<75 \%$ & $63(21.6 \%)$ & 116(39.7\%) & $51(17.5 \%)$ & \multirow[t]{2}{*}{3.57} \\
\hline & $>75 \%$ & $10(3.4 \%)$ & $38(13.0 \%)$ & $14(4.8 \%)$ & \\
\hline \multirow[t]{2}{*}{$\begin{array}{l}\text { Average hour of sleep } \\
\text { during last one month }\end{array}$} & $\begin{array}{l}\text { Less than } 8 \\
\text { hours }\end{array}$ & $64(21.9 \%)$ & $136(46.6 \%)$ & $57(19.5 \%)$ & \multirow[t]{2}{*}{.02} \\
\hline & $\begin{array}{l}\text { More than } 8 \\
\text { hours }\end{array}$ & $9(3.1 \%)$ & $18(6.2 \%)$ & $8(2.7 \%)$ & \\
\hline \multirow[t]{2}{*}{ Settings } & Rural & $24(8.2 \%)$ & $44(15.1 \%)$ & $23(7.9 \%)$ & \multirow[t]{2}{*}{1.12} \\
\hline & Urban & $49(16.8 \%)$ & $110(37.7 \%)$ & $42(14.4 \%)$ & \\
\hline \multirow[t]{2}{*}{ Daily exercise } & Yes & $48(16.4 \%)$ & 115(39.4\%) & $49(16.8 \%)$ & \multirow[t]{2}{*}{2.30} \\
\hline & No & $25(8.6 \%)$ & $39(13.4 \%)$ & $16(5.5 \%)$ & \\
\hline
\end{tabular}

$*_{\mathbf{f}}=$ frequency $\%=$ percentages

\section{DISCUSSION}

This research basically emphasise upon the stress among undergraduate medical students. Huge studies have been shown in western countries to evaluate the levels of stress and other mental health related variables. According to study medical students mostly feel stress, because they are busy, difficult targets to achieve and they have an important deadline to meet. Disaster, major life changes, daily difficulties are some causes of stress in Medical students (Rana MH, Mustafa M 2013)

In our study all of the medical students were found to be stressed, while another study which has been reported 88\% students as stressed ( F Sabih-2013).Stress can affect a person's efficiency either by increasing it ('eustress') or decreasing it ('distress') .Stress shows beneficial effects in females when compared to males. (Kumar M, Sharma S - 2014) In our study the level of stress differs in nature and severity. On the basis of this finding, Moderate stress was the most common level of stress found in the students of Rawalpindi medical college, where another study (Sabih F, Siddiqui FR, Baber MN 2013) has also shown the same results.

Psychological counselling is suggested for the medical students having moderate and severe level of stress. One of the bases of the current study is its approach to defining the suggestion of demographic factors like gender, age, percentage in the last examination boarding status, , marital status, and average hours of sleep, family average monthly income, living setting, and

(C) The International Journal of Indian Psychology, ISSN 2348-5396 (e)| ISSN: 2349-3429 (p) | 99 


\section{Level of Stress and Its Association with Socio-Demographic Factors among Medical Students of Rawalpindi Medical College}

daily exercise with stress. The effect of gender on stress in students of the health professions differs. According to our study Female students were more stressed as compared to male students, which is statistically significant. In contrast, some previous studies also suggest that there were significant gender differences as well, with the women reporting higher levels of stress than male (Towes MD, Lockyes JM, Dobson DJ-1997)

Females not only differ in their thought of stressors as they perceive more pressures as compare to male, but their reactions to stressors are also different. They seem to be more openly reactive. This might be due to the reason that majority of the students in this discipline were females and due to high physical demand of this field, females' possess high level of stress Mostly in our culture males are ordinary to suppress their emotions. For this reason male has lower psychological and emotional reactions to stressors due to their socialization. (Sabih F, Siddiqui FR, Baber MN 2013) While other studies do not reveal any gender differences (Misra R ,McKean M-2000 and Toews JA, Lockyer JM, 1997).Modifications in the level of stress were also found along with the year of study. On the basis of year of education our study shows highest frequency in the $3^{\text {rd }}$ year and 4 th year students and it seems to be moderately stressed. In our study all of the students were found to be stressed but the stress increase in 4th semester which shows gradually getting a difficult syllabus in the later semesters including clinical work which demands more attention and energy But this study results is slightly in contrast or different from our study in which reveals a significant increase in the proportion of students and the level of stress was high in third year as compared to the first year (Ludwig AB, Burton W2015)

In our study we find the severity of stress through sociodemographic factors. According to the results students having less than $75 \%$ marks in last examination were found to have relatively high level of stress. Students who do not exercise regularly were found to have less level of stress as compared to students who do. In contrast as the exercising 3-5 times a week conditions you to deal with stress by using up the body's physical stress response. (Rana MH and Mustafa M-2013).Students belonging to urban background were found to possess high level of stress as compared to students of rural background. While other study results shows that rural background were found more level of stress (Badur-un-Nisa1, M. Kashif -2016)

In our study students who have an average sleep of less than 8 hours reported to have more level of stress. Another study have shown that sleep deficiency and sleep control are conditions often connected with mild, temporary increases in the activity of the major neuroendocrine stress systems ( Meerlo P, Sgoifo A-2008)

Medical students may feel stress, because they are hard, difficult targets to attain and most of them come from another city. In our study we found that students who were boarders reported to

(c) The International Journal of Indian Psychology, ISSN 2348-5396 (e)| ISSN: 2349-3429 (p) | 100 


\section{Level of Stress and Its Association with Socio-Demographic Factors among Medical Students of Rawalpindi Medical College}

have higher level of stress as compared to students who were day scholar. This study Results is in favor of our study that females face more stressors and stress was more significant between boarders as compare to non-boarders (R.Farah, F Sabih F, Farooq K- 2009)

We conducted this study which will help to improve greater personal responsiveness of student's types of personal and academic stressors that they are facing, while being medical students. It is vital to give unusual attention on psychological wellbeing of our students and it is as important as physical health. It is obvious from the above results that significantly higher level of stress is found in students of Rawalpindi Medical College. The statistics highlight stress as the major health concern among medical students. Stress in student's particularly medical students needs to be talked. Aerobic exercises, relaxation, biofeedback, social support, and coping strategies are few methods to cope with stress .Energetic programs should be expressed to avoid this issue. Disturbed authority need to undertake actual measures to prevent stress among medical students. The most important work is to start the stress management workshops, which should be conducted regularly. Future research should also focus on ways of increasing student's ability to cope with the stressors of medical students.

\section{CONCLUSION}

Stress was present in all the medical students who participated in the study. Moderate stress being the commonly prevalent and it was more common in female students as compared to male students, irrespective of academic years. Findings also reveal that female's face more stressors especially on self-imposed and frustrations $(\mathrm{p}=0.00)$

\section{Acknowledgment:}

We would like to record our appreciation to all people that involve in the writing of this report, We would like to thank all medical students of RMC of their participation in the activity.

\section{Conflict of Interests}

The author declared no conflict of interests.

\section{REFERENCES}

Abdulghani, H., AlKanhal, A., Mahmoud, E., Ponnamperuma, G., \& Alfaris, E. (2011). Stress and Its Effects on Medical Students: A Cross-sectional Study at a College of Medicine in Saudi Arabia. Journal Of Health, Population And Nutrition, 29(5).

Eva, E., Islam, M., Mosaddek, A., Rahman, M., Rozario, R., \& Iftekhar, A. et al. (2015). Prevalence of stress among medical students: a comparative study between public and private medical schools in Bangladesh. BMC Research Notes, 8(1).

Franken, R. (2007). Human motivation (1st ed.). Australia: Thomson/Wadsworth.

Gaurav Akrani. Date: 3/27/2011 Industrial Psychology. what-is-stress-meaning-definitionand.html 


\section{Level of Stress and Its Association with Socio-Demographic Factors among Medical Students of Rawalpindi Medical College}

Kumar M, Sharma S, Gupta S, Vaish S, Misra R.(2014). Effect of stress on academic performance in medical students--a cross sectional study. Indian J Physiol Pharmacol, 58(1):81-86. 21.

Ludwig, A., Burton, W., Weingarten, J., Milan, F., Myers, D., \&Kligler, B. (2015). Depression and stress amongst undergraduate medical students. BMC Medical Education, 15(1).

Meerlo, P., Sgoifo, A., \& Suchecki, D. (2008). Restricted and disrupted sleep: Effects on autonomic function, neuroendocrine stress systems and stress responsivity. Sleep Medicine Reviews, 12(3), 197-210. http://dx.doi.org/10.1016/j.smrv.2007.07.007

Misra R and McKean M. (2000) College students' academic stress and its relationship to their anxiety, time management, and leisure satisfaction. American Journal of Health Studies; 16(1), 41-51. http://dx.doi.org/10.1016/j.smrv.2007.07.007

Nisa, B., Kashif, M., \& Khan, T. (2016). Level of Stress and its Association with SocioDemographic Factors Among Students of Allied Health Sciences. Journal of Rawalpindi Medical College Students Supplement, 2(20(S-1), 27-30.

Niemi, P. \&Vainiomäki, P. (1999). Medical Students' Academic Distress, Coping, and Achievement Strategies During the Preclinical Years. Teaching And Learning In Medicine, 11(3), 125-134. http://dx.doi.org/10.1207/s15328015tl110302

Omigbodun, O., Odukogbe, A., Omigbodun, A., Yusuf, O., Bella, T., \& Olayemi, O. (2006).Stressors and psychological symptoms in students of medicine and allied health professions in Nigeria. Social Psychiatry And Psychiatric Epidemiology, 41(5), 415-421. 3

Rana, M., Ali, S., \& Mustafa, M. (2012). A handbook of behavioural sciences for medical \& dental students. Lahore: University of Health Sciences. http://dx.doi.org/10.1080/0142159031000136716

Sabih, F., Siddiqui, F., \& Baber, M. (2013).Assessment of stress among physiotherapy students at Riphah Centre of Rehabilitation Sciences. J Pak Med Assoc, 63(3).

Saipanish, R. (2003). Stress among medical students in a Thai medical school. Medical Teacher, 25(5), 502-506.

Sreeramareddy, C., Shankar, P., Binu, V., Mukhopadhyay, C., Ray, B., \& Menezes, R. (2007). Psychological morbidity, sources of stress and coping strategies among undergraduate medical students of Nepal. BMC Medical Education, 7(1). http://dx.doi.org/10.1186/1472-6920-7-26.).

Towes MD, Lockyes JM, Dobson DJ, Sinpson E, Brownell AK, Brenncis F, et al. (1997) Analysis of stress levels among medical students residents and graduate students at four Canadian school of medicine. Acad Med; 72: 997-1002

How to cite this article: Kashif, M, Fatima M, Nisa B, Hassan S, Ghazal I, Aslam F (2016), Level of Stress and Its Association with Socio-Demographic Factors among Medical Students of Rawalpindi Medical College, International Journal of Indian Psychology, Volume 4, Issue 1, No. 82, ISSN:2348-5396 (e), ISSN:2349-3429 (p), DIP:18.01.150/20160401, ISBN:978-1-36559365-9

(c) The International Journal of Indian Psychology, ISSN 2348-5396 (e)| ISSN: 2349-3429 (p) | 102 